\title{
The Effect of the Superordinate Concept and Presentation Form of Examples on Concept Learning
}

\author{
Frederik J. A. Ranzijn \\ University of Twente, Department of Education
}

\begin{abstract}
In the research reported here, the effects of the presentation of the more general (superordinate) concept on the attainment of basic concepts, and the effects of two different forms of example presentation on concept learning were studied. In one condition, examples were presented as line drawings on a microcomputer monitor. In the other condition the example was presented 'real life' on a video monitor. It was found that presenting the superordinate concept reduced the time needed to study new information. However, it had no effect on the retention test classification scores. The realistic, interactive video presentation of examples led to better classification scores on the retention test. This study shows that computer based instruction in combination with interactive video are useful instructional means.
\end{abstract}

In the classical view of concept learning a concept is described by separately necessary and jointly sufficient properties (Smith \& Medin, 1981). Those properties of the objects used in a classification rule are the defining or relevant properties, the others are the variable or irrelevant properties. Experiments designed to study concept learning in the classical tradition always used completely defined, artificial concepts. The set of objects to be classified almost always consisted of a finite number of objects, particularly geometrical figures, and were used to study the external conditions of concept learning (i.e., the characteristics of the set of objects and the relationship between the characteristics).

Criticism of the classical view with completely defined concepts led to the development of the prototype theory (Neumann, 1974, 1977; Posner \& Keele, 1968; Rosch, 1978; Rosch \& Mervis, 1975). This theory focuses more on natural categories with fuzzy boundaries. In this view not all objects of a category are equally representative and the properties are not necessarily shared by all objects, rather objects vary in the degree in which they are judged to be good examples of the category.

\footnotetext{
This study was supported by a grant from the Institute for Educational Research in the Netherlands (SVO), Grant No. 6620. I wish to thank S. Dijkstra, H. H. Leemkuil, and D. Poppe, for their assistance during this project. I also wish to thank the students, the biology teacher and the management of the Scholengemeenschap Zuid, Enschede, The Netherlands, for their friendly cooperation.
}

Requests for reprints should be addressed to Frederik J. A. Ranzijn, University of Twente, Department of Education, P.O. Box 217, 7500 AE Enschede, The Netherlands. 
Neumann (1977) defined the prototype or best example as that pattern which incorporates the most frequently experienced value on each of the dimensions of variability. Rosch (1978) suggested that categories are coded in memory at basic levels of abstraction, which are the most inclusive, and at a general level in which objects contain common properties (critical and variable properties). In determining category membership a subject pays attention to both the defining properties and the variable properties of the object.

Most research on concept learning is done by teaching subjects a new concept or concepts and studying the learning process. The rules for instructional design for concept learning closely follow the classical view (i.e., they are mainly fixed to the defining properties). Klausmeier and his collaborators (Klausmeier, Ghatala \& Frayer, 1974; Klausmeier \& Sipple, 1980) presented a cognitive theory of learning and development. In their instructional design rules, they focus mainly on the concept definition and the defining properties. According to the instructional design guide of Merrill and Tennyson (1977), the most effective way to teach a concept is to present a definition, followed by several examples and some practice in categorizing.

Tennyson, Youngers, and Suebsonthi (1983) showed how the prototype theory is applied to instructional design. They presented a theory of concept learning that includes two learning processes: formation in the memory of information representative of a given concept class and the development of the cognitive skills of generalization and discrimination.

In an experiment to study which instructional presentation form will facilitate the learning of conceptual information they conclude that "in an initial exposure to a concept, a best example may facilitate encoding of a clear prototype from which learners can both add specific dimensions and begin classification-skill development." In addition, they concluded that presentation of a best example is preferable to presenting an operational rule that offers the relationship between the concept definition and the critical properties. The learner encodes an abstraction of the concept class as a prototype and the dimensionality of the prototype in relation to the variable descriptors is elaborated by presenting successive examples. In this study, the concept 'regular polygon' was taught. This concept has only two variable attributes (size, and the number of angles).

Most natural categories (animals, plants, etc.) have more than one or two variable attributes and the objects from a natural category do not share all defining properties. This makes it unclear which example of a category would be the best, and hence selecting the best example is not always possible. Therefore, in teaching natural categories the teacher should present more than one example.

Tennyson et al. (1983) assume concept learning is a two-phase process: (a) the formation of conceptual knowledge (i.e., the integrated storage of meaningful dimensions selected from known examples), and (b) the development of procedural knowledge by using conceptual knowledge to solve domain-specific problems (Tennyson \& Cocchiarella, 1986).

The presentation form of examples varies. First by presenting the real object, second by showing a realistic representation of the object (photograph or film), or, finally, by presenting a schematic representation (a line drawing). Presenting the real object sometimes is difficult or impossible if the object is very large or not available. With the presentation of a photograph of a static object, or a film of a moving object or process, the variable attributes are still available and prototype 
formation is still possible. In a schematic representation of the object most variable attributes are stripped of the object and prototype formation is impaired or impossible.

The first goal of the study reported here was to test how prototype formation is effected by the presentation form of the examples. In relation to the findings of Tennyson et al. $(1983,1986)$, it was hypothesized that prototype formation is facilitated if subjects are able to pay attention to both the defining attributes as well as to the variable attributes of the object in a realistic presentation on video. Consequently, these subjects would perform better on a categorization test than subjects who had a schematic presentation of the examples.

It is supported that the expected beneficial effect in the video-condition will not be noticed on an immediate posttest. Because of the 'freshness' of the new information all subjects will perform equally well. After some time a decrease of declarative knowledge (knowing what the defining characteristics are) will be noticed with all subjects. However, for the procedural knowledge (the ability to classify instances correctly) we expect that subjects in the video condition will perform better on a retention test than subjects in the 'schematic' condition because of a better consolidated prototype.

The second objective of this study was to test whether presenting the superordinate concepts in the instruction would help in the comprehension of the subordinate or basic level concepts and whether this approach would lead to a better understanding and classification skill.

Previously acquired knowledge can facilitate the learning and assimilation of new subordinate knowledge (Ausubel, 1968; Mayer, 1977). In a similar way Anderson, Spiro, and Anderson (1978) stated that the schemata the student already has, will primarily determine the new information the student is able to learn. Reigeluth and Stein (1983) stated that instructional designers should be aware of this phenomenon and write instructions in such a way that in a conceptually organized course the most general concepts should be presented in an epitome and successive elaborations should provide more detailed and narrow subclassifications of these concepts until the most detailed concepts are mastered.

To test whether presenting the superordinate concept enhanced the comprehension of the basic level concepts the first concept was presented to the experimental group prior to the presentation of the basic level concepts. It is hypothesized that the information presented in the introduction provides the subject with an anchoring point to which the new information can be connected and subsumed. As a consequence, subjects who have had this introduction will spend less time studying the paragraphs concerning the new concepts. On the retention tests a better performance on the declarative knowledge and procedural knowledge tests is expected.

\section{METHOD}

\section{Subjects}

Sixty subjects between the ages of 12 and 14 years participated in this study. They were male and female pupils of a Dutch secondary school. Participation in this study was compulsory. The scores on the tests, however, were not included in their school grades. The subjects were randomly assigned to the conditions. 


\section{Instructional Program}

An instructional computer program describing pollination was designed. The concepts to be learned were: wind-flowers (flowers of which the pollen is transported by the wind) and insect-flowers (flowers of which the pollen is transported by insects). The.instructional program was developed with the PETRIL authoring system (Sikken, 1987), and consists of paragraphs describing the following concepts: general reproduction (only in the 'with introduction' condition), flower structure (here we taught the subjects about the stamen, another, pistil, stigma, etc.), pollination (a more detailed instruction was given in the 'with-introduction' condition), the concept of a wind-flower, the concept of an insect-flower, a synthesis, in which the information about the wind-flowers and insect-flowers was summarized, and a small test in which some declarative knowledge about the concepts wind-flower and insect-flower was examined. The subject matter had not yet been taught in a classroom setting.

All the instructional paragraphs consisted of several successively presented windows with text, in some cases accompanied by a line drawing, and a question about the content of that window. This question was an 'attention focusing' question and it was also a means to be sure that the subject did actually read the text. The next window was presented only if the question was answered correctly.

The paragraphs concerning wind-flowers and insect-flowers started with a window about the particular concept in general. Next, the defining characteristics were explained, one at a time. After answering the question, an example was presented. The examples each had a duration of 20 seconds. The text accompanying the examples in the line drawing condition were spoken in the video fragments.

\section{Tests}

Two tests were designed. A post-test, administered immediately after presenting the instructional program, and a retention test, administered two months later. On both occasions the same two tests were presented: a test of procedural knowledge and a test of declarative knowledge.

Test of procedural knowledge. Two classification tests were designed, test A and test $\mathrm{B}$, both consisting of 17 photographs of wind-flowers and 18 photographs of insect-flowers. Insect-flowers usually have very salient colors (yellow, red, etc.), and wind-flowers are often greenish or brownish. Just paying attention to the color characteristic could possibly result in a high score. By also presenting pictures in black and white, the effect of the color cue was controlled. In test $A$ of the windflowers, there were eight pictures in black and white and nine pictures in color. In test $B$ of the wind-flowers, there were nine pictures in black and white and eight pictures in color. In both tests of the insect-flowers nine pictures were in black and white and nine pictures were in color. A black and white picture in test A appeared in color in test $B$ and vice versa.

Test of declarative knowledge. In this test the subject had to recall the characteristics of the two types of flowers and give some examples of both.

\section{Apparatus}

The instructional program ran on an Apple Macintosh Plus (1Mb) microcomputer, connected with a Panasonic AG-6200 videorecorder, using a BCD-controller as interface. The video pictures were presented on a Philips CM8833 color-monitor. 


\section{Design}

A $3 \times 2$ factorial design was used to test the hypotheses. The first independent variable had three levels: an interactive video condition, in which the examples in the instructional computer program were presented 'real life' on a video monitor and a line drawing condition in which the examples were presented as line drawings on a microcomputer screen. The third level was designed to control the possible effects of the presence of the equipment in video condition. This might have an attention or motivation arousing effect on the subjects and the results could be due to this and not to the differences in presentation of examples. In the control condition the same instruction was presented to the subjects, with examples of the same instances as in the other two conditions. However, because the object was not 'zoomed in,' detailed visual information was withheld to prevent prototype formation. Performance of these subjects thus cannot be based on a prototype. Therefore, if subjects in the control condition perform better than subjects in the line drawing condition, an 'apparatus-effect' can be assumed.

The second independent variable comprised two levels. In the experimental condition the subject was presented with a general introduction to reproduction, and an extended description of pollination in which the correspondence with the general principle of reproduction was elucidated. In the control condition there was no reference to reproduction at all and only the most necessary information about pollination was given. Both levels received the same information about the other concepts (wind-flowers and insect-flowers).

\section{Procedure}

The subjects first ran a computer program that explained to them how to work with the computer (typing text, using help-menus, etc.). Each subject then individually studied the instructional program. The experimenter was positioned in such a way that he could follow the progress and read the answers the subject gave to the questions. If the subject did not manage to answer a question correctly during the instruction after three trials the experimenter focused the subject's attention to the relevant instructional statement. After the instruction one of the two classification tests was presented. Thirty subjects received test A and another thirty received test $B$. After the classification test, the declarative knowledge test was given. After a two month interval, subjects participated in a retention test session.

\section{Data}

Program data. During the instruction the program created a logging file in which the time spent studying each concept, and the typing time in each paragraph was recorded. The typing time was subtracted from the instruction time per paragraph as it was assumed that when the subject started typing the answer to the question, processing of the information stopped, and so the 'real' instruction time was estimated.

Procedural knowledge data. Of each item in the classification test the $p$-value on the immediate posttest was calculated. If the $p$-value of an item was not between .20 and .80 on test $\mathrm{A}$ as well as on test $\mathrm{B}$, it was excluded from further analysis.

In both tests, 15 items were included, eight pictures of wind-flowers and seven pictures of insect-flowers. In test $A$, of the wind-flowers five pictures in black and 
white and three pictures in color were left. Of the insect-flowers, three pictures were in black and white and four pictures were in color. In test B of the wind-flowers, there were three pictures in black and white and five pictures in color. Of the insect-flowers, four pictures were in black and white and three pictures were in color.

The following scores were obtained with the classification test: the number of correctly classified color pictures of wind-flowers (COL.WIND), black and white pictures of wind-flowers (BLW.WIND), color pictures of insect-flowers (COL.INS), black and white pictures of insect-flowers (BLW.INS). Finally, three total scores were calculated: the total correctly classified wind-flowers (WIND.TOT), the total correctly classified insect-flowers (INS.TOT), and the total correct classifications (TOTAL).

Declarative knowledge data. The declarative knowledge test resulted in six scores: the number of correctly mentioned defining characteristics of each concept (CHAR.WIND, CHAR.INS), the number of examples given that were also used as examples in the program (i.e., recalled examples (WIND.REC, INS.REC)), and the number of new or generated examples (WIND.GEN, INS.GEN).

Difference scores. For the procedural and declarative knowledge variables the difference between the score on the retention test and the immediate post test was calculated. A positive difference score means a better performance on the retention test. A negative difference score means a better performance on the immediate posttest.

\section{RESULTS}

\section{Program Data}

An univariate analysis of variance (ANOVA) showed that the introduction had a significant effect on the time spent on the paragraph concerning wind-flowers $(F(1,51)=4.33, p<.04)$, the synthesis $(F(1,51)=5.24, p<.02)$, and a smaller effect on the paragraph concerning insect-flowers $(F(1,51)=2.55, p<.11)$. This means that the subjects who had the introduction spent less time studying these paragraphs (see Table 1). On the whole, the subjects in the 'with introduction' condition spent more time on the full instruction than subjects in the "without introduction' condition $(F(1,51)=6.06 p<.01)$.

\section{Procedural Knowledge}

As expected, an analysis of variance (ANOVA) on the classification test scores revealed no significant differences on the immediate posttest.

On the retention test a univariate analysis of variance showed that the introduction had no effect on the classification scores. The example presentation form has a significant effect on three variables: TOTAL, WIND.TOT and COL.WIND (see Table 2 and Table 3 ).

In Table 4 the mean difference scores between color and black and white pictures on the immediate posttest and the retention test are presented. The Student's $t$-test was used to compare these difference scores. It was found that in almost all conditions, on the immediate posttest, the color pictures of insect-flowers were bet- 
Table 1. Mean Instruction Times (in Sec.)

\begin{tabular}{|c|c|c|c|c|c|c|}
\hline \multirow[b]{3}{*}{ Section } & \multicolumn{6}{|c|}{ Condition } \\
\hline & \multicolumn{2}{|c|}{ Video } & \multicolumn{2}{|c|}{ Line Drawing } & \multicolumn{2}{|c|}{ Control } \\
\hline & With & Without & With & Without & With & Without \\
\hline \multicolumn{7}{|l|}{ Reproduction } \\
\hline Mean & 369.5 & - & 358.1 & - & 364.0 & - \\
\hline$S D$ & 196.0 & - & 116.4 & - & 138.8 & - \\
\hline \multicolumn{7}{|c|}{ Flower structure } \\
\hline Mean & 282.9 & 396.3 & 340.4 & 301.1 & 325.1 & 396.6 \\
\hline$S D$ & 68.6 & 154.9 & 138.1 & 88.0 & 70.3 & 57.9 \\
\hline \multicolumn{7}{|l|}{ Pollination } \\
\hline Mean & 239.8 & 65.7 & 241.8 & 64.7 & 233.4 & 61.7 \\
\hline$S D$ & 94.0 & 18.0 & 77.1 & 30.5 & 21.9 & 17.2 \\
\hline \multicolumn{7}{|l|}{ Insect-flower } \\
\hline Mean & 759.3 & 873.4 & 787.7 & 822.5 & 851.6 & 1043.3 \\
\hline$S D$ & 127.8 & 182.3 & 151.8 & 298.3 & 149.2 & 466.0 \\
\hline \multicolumn{7}{|l|}{ Wind-flower } \\
\hline Mean & 730.6 & 902.6 & 697.6 & 819.9 & 811.9 & 877.3 \\
\hline$S D$ & 217.0 & 246.1 & 152.8 & 206.2 & 168.4 & 289.6 \\
\hline \multicolumn{7}{|l|}{ Synthesis } \\
\hline Mean & 127.7 & 167.3 & 119.7 & 153.2 & 134.1 & 171.9 \\
\hline$S D$ & 29.6 & 75.4 & 33.6 & 54.4 & 42.7 & 64.1 \\
\hline \multicolumn{7}{|l|}{ Test } \\
\hline Mean & 344.5 & 351.2 & 277.1 & 324.5 & 376.5 & 308.0 \\
\hline$S D$ & 68.6 & 108.6 & 89.8 & 115.8 & 192.8 & 94.6 \\
\hline \multicolumn{7}{|l|}{ Total } \\
\hline Mean & 1726.3 & 1575.9 & 1697.6 & 1408.1 & 1624.4 & 1601.6 \\
\hline SD & 348.7 & 255.7 & 420.2 & 366.3 & 334.8 & 284.4 \\
\hline
\end{tabular}

Note: Subjects in the 'without introduction' conditions did not receive an instruction on 'reproduction in general.' On 'pollination' a more detailed instruction was given in the 'with introduction' conditions.

ter classified than the black and white pictures of insect-flowers. The opposite can be noticed regarding the wind-flowers, that is, the black and white pictures are classified slightly better than the color pictures.

\section{Declarative Knowledge}

Univariate analysis of variance revealed no significant effect of either the example presentation form or the presentation of the superordinate concept (in the introduction) on the scores of the 'declarative knowledge questionnaire,' neither on the immediate posttest nor on the retention test.

\section{Difference Scores}

Univariate analysis of variance of the difference scores showed no effects of the independent variables. Generally, the mean differences for the declarative knowledge data are negative (a decrease), and the mean differences for the procedural knowledge data are positive (an increase). 
Table 2. ANOVA Results-Effect: Example Presentation Form

\begin{tabular}{lrrrr}
\hline & \multicolumn{2}{c}{ Post-Test $^{\mathrm{a}}$} & & \multicolumn{2}{c}{ Retention $^{\text {Vest }}{ }^{\mathrm{b}}$} \\
\cline { 2 - 4 } Variable & $F$ & $p<$ & $F$ & $p<$ \\
\hline COL.WIND & 1.30 & .28 & 2.56 & .08 \\
BLW.WIND & .17 & .84 & .56 & .57 \\
COL.INS & 1.11 & .33 & .49 & .61 \\
BLW.INS & .19 & .82 & .48 & .61 \\
WIND.TOT & .56 & .57 & 2.70 & .07 \\
INS.TOT & .82 & .44 & .90 & .40 \\
TOTAL & .28 & .75 & 2.64 & .08 \\
\hline
\end{tabular}

${ }^{a} d f=2,51$.

${ }^{b} d f=2,54$.

\section{DISCUSSION}

Presenting the superordinate concept first, in order to enable the student to connect the new information to already acquired knowledge, clearly has a reducing effect on the presentation time of the instruction. However, it was not found that subjects who had been presented the superordinate concept performed better on the retention tests than subjects who had not been presented with this concept. It is possible that subjects who were not presented the introduction, were for a cer-

Table 3. Mean Classification Scores on the Retention Test

\begin{tabular}{|c|c|c|c|}
\hline \multirow[b]{2}{*}{ Condition } & \multicolumn{3}{|c|}{ Variable } \\
\hline & COL.WIND & WIND.TOT & TOTAL \\
\hline \multicolumn{4}{|l|}{ With Introduction } \\
\hline $\begin{array}{l}\text { Mean } \\
S D\end{array}$ & $\begin{array}{l}2.90 \\
1.37\end{array}$ & $\begin{array}{l}6.60 \\
2.01\end{array}$ & $\begin{array}{r}11.30 \\
1.88\end{array}$ \\
\hline $\begin{array}{l}\text { Linedrawing } \\
\text { Mean } \\
S D\end{array}$ & $\begin{array}{l}2.33 \\
1.58\end{array}$ & $\begin{array}{l}5.33 \\
2.12\end{array}$ & $\begin{array}{l}9.00 \\
2.23\end{array}$ \\
\hline $\begin{array}{c}\text { Control } \\
\text { Mean } \\
S D\end{array}$ & $\begin{array}{r}1.80 \\
.91\end{array}$ & $\begin{array}{l}4.70 \\
1.25\end{array}$ & $\begin{array}{l}8.90 \\
1.52\end{array}$ \\
\hline $\begin{array}{l}\text { Without Introdu } \\
\text { Video } \\
\text { Mean } \\
S D\end{array}$ & $\begin{array}{l}3.00 \\
1.56\end{array}$ & $\begin{array}{l}5.90 \\
2.64\end{array}$ & $\begin{array}{r}10.30 \\
3.05\end{array}$ \\
\hline $\begin{array}{l}\text { Linedrawing } \\
\text { Mean } \\
S D\end{array}$ & $\begin{array}{l}2.18 \\
1.47\end{array}$ & $\begin{array}{l}5.27 \\
1.84\end{array}$ & $\begin{array}{l}9.72 \\
2.57\end{array}$ \\
\hline $\begin{array}{l}\text { Control } \\
\text { Mean } \\
S D\end{array}$ & $\begin{array}{l}2.20 \\
1.22\end{array}$ & $\begin{array}{l}4.90 \\
1.91\end{array}$ & $\begin{array}{l}9.90 \\
1.85\end{array}$ \\
\hline
\end{tabular}


Table 4. Difference Scores Between Color and Black and White Pictures

\begin{tabular}{|c|c|c|c|}
\hline \multirow[b]{2}{*}{ Condition } & \multicolumn{3}{|c|}{ Example Presentation } \\
\hline & Video & Line Drawing & Control \\
\hline With Introduction & \multicolumn{2}{|c|}{ Immediate Post Test } & \\
\hline $\begin{array}{l}\text { wind-flowers } \\
\text { insect-flowers }\end{array}$ & $\begin{array}{r}-.22 \\
.00\end{array}$ & $\begin{array}{l}-.25 \\
1.00^{\mathrm{b}}\end{array}$ & $\begin{array}{c}-1.20^{a} \\
.90\end{array}$ \\
\hline \multicolumn{4}{|l|}{ Without Introduction } \\
\hline $\begin{array}{l}\text { wind-flowers } \\
\text { insect-flowers }\end{array}$ & $\begin{array}{l}-.10 \\
1.30^{\mathrm{b}}\end{array}$ & -.36 & -.60 \\
\hline \multirow{2}{*}{\multicolumn{4}{|c|}{ Retention Test }} \\
\hline With Introduction & & & \\
\hline wind-flowers & -.80 & -.66 & $-1.10^{\mathrm{a}}$ \\
\hline insect-flowers & -.10 & .33 & .40 \\
\hline \multicolumn{4}{|l|}{ Without Introduction } \\
\hline wind-flowers & .10 & $-.90^{\mathrm{a}}$ & -.50 \\
\hline insect-flowers & .60 & .45 & .40 \\
\hline
\end{tabular}

${ }^{a} p<.05$.

${ }^{\mathrm{b}} p<.01$, one tailed.

Note: A positive difference score means that colored pictures are better classified and a negative score means that black and white pictures are better classified.

tain extent familiar with the principle of reproduction and made the connection with the new information themselves, which may explain the insignificant result.

The results show that new information is assimilated faster if the domain of that information firstly is sketched out. Based on this result it is suggested that if the superordinate concept is familiar, one should offer students a short presentation of this concept. This is supported by the findings of Tennyson and Park (1987). They stated that advance organizers are usually too extensive to keep in memory simultaneously with the acquisition of new information. They further suggest that providing direct information about the specific prerequisite knowledge is helpful at the moment of learning.

The use of a prototype is supported by the increasing procedural knowledge scores on the retention test while the declarative knowledge scores are decreasing as compared to the scores of the immediate posttest. Starting out from the classical point of view the classification test would be performed based on separately necessary and jointly sufficient properties, that is, on declarative knowledge. However, the procedural knowledge is increasing while the declarative knowledge is not. The classical point of view is unable to solve these 'contrasting' results since an increase in classification score can only be achieved if also an increase in declarative knowledge is measured. Prototype theory can deal with this "classical" dilemma. The difference in procedural knowledge scores is explained by a better consolidated prototype for subjects in the video condition.

On the immediate posttest, a difference is found between the number of correctly classified color pictures of a category and the number of correctly classified black and white pictures. If a test item is in color, subjects tend to classify it as an insectflower and if the test item is in black and white it is likely to be classified as a wind- 
flower. The subjects pay most attention to the color attribute. On the retention test most of these differences disappear. This result also supports the effect of a prototype, because all stored features are used for later categorization. Color is no more a dominant feature for categorization.

The hypothesis that the presentation of visually richer or more realistic examples would lead to a richer or better consolidated prototype is confirmed. The results of this study show that in case of natural categories the object being presented should be a realistic object. An example, at least for learning natural concepts, has to contain also contextual, nondefining features. This contrasts with the view that in instruction one should present only the relevant cues (e.g., Dwyer, 1972).

The results of this experiment show a substantial effect of the example presentation form on the retention of the procedural knowledge. On the retention test, subjects in the video condition perform best. The example presentation form has no effect on the retention of the declarative knowledge. It is supposed that the dynamic presentation on video of the process of pollination, showing both relevant and irrelevant features causes the better retention. Video is adequate for showing a process, because it promotes the mental representation of the process.

Generally, in teaching natural categories, effort should be made to produce a prototype or prototypical effects. This can be done by presenting realistic examples in which the student can pay attention to the critical, defining, as well as to the irrelevant, contextual attributes. This study also shows us that computer-based instruction and interactive video are useful instructional aids. The use of interactive video offers students the possibility to study realistic objects. In teaching complex visual material or processes one should use audio-visual aids to induce a better comprehension.

\section{REFERENCES}

Anderson, R.C., Spiro, R.J., \& Anderson, M.J. (1978). Schemata as scaffolding for the representation in connected discourse. American Educational Research Joumal, 15, 433-440.

Ausubel, D.P. (1968). Educational psychology: A cognitive view. New York: Holt, Rinehart \& Winston.

Dwyer, F.M. 1972). A guide for improving visualized instruction. State College, PA: Learning Services.

Klausmeier, H.J., Ghatala, E.S., \& Frayer, D.A. (1974). Conceptual learning and development: A cognitive view. New York: Academic Press.

Klausmeier, H.J., \& Sipple, T.S. (1980). Learning and teaching concepts: A strategy for testing applications of a theory. New York: Academic Press.

Mayer, R.E. (1977). The sequencing of instruction and the concept of assimilation-to-schema. Instructional Science, 6, 369-388.

Merrill, M.D., \& Tennyson, R.D. (1977). Teaching concepts: An instructional design guide. Englewood Cliffs, NJ: Educational Technology Publications.

Neumann, P.G. (1974). An attribute frequency model for the abstraction of prototypes. Memory and Cognition, 5, 187-197.

Neumann, P.G. (1977). Visual prototype formation with discontinuous representation of dimensions of variability. Memory and Cognition, 5, 187-197.

Posner, M.I., \& Keele, S.W. (1968). On the genesis of abstract ideas. Journal of Experimental Psychology, 77, 353-363.

Reigeluth, C.M., \& Stein, F.S. (1983). The elaboration theory of instruction. In C.M. Reigeluth (Ed.), Instructional-design theories and models: An overview of their current status (pp. 279-333). Hillsdale, NJ: Lawrence Erlbaum Associates. 
Rosch, E. (1978). Principles of categorization. In E. Rosch, \& B.B. Lloyd (Eds.), Cognition and categorization (pp. 27-48). Hillsdale, NJ: Erlbaum.

Rosch, E., \& Mervis, C.B. (1975). Family resemblances: Studies in the internal structure of categories. Cognitive Psychology, 7, 573-605.

Sikken, J. (1987). MPW petril manual [Computer program manual]. Enschede, The Netherlands: University of Twente, Department of Education.

Smith, E.E., \& Medin, D.L. (1981). Categories and concepts. Cambridge, MA: Harvard University Press.

Tennyson, R.D., Cocchiarella, M.J. (1986). An empirically based instructional design theory for teaching concepts. Review of Educational Research, 56, 40-71.

Tennyson, R.D., \& Park, O. (1987). Artificial intelligence and computer-based learning. In R.M. Gagné (Ed.), Instructional technology: Foundations (pp. 319-342). Hillsdale, NJ: Erlbaum.

Tennyson, R.D., Youngers, J., \& Suebsonthi, P. (1983). Concept learning by children using instructional presentation forms for prototype formation and classification-skill development. Journal of Educational Psychology, 75, 280-291. 